\title{
Os conteúdos de ensino da educação física na perspectiva dos estudantes: uma revisão sistemática de produções da área ${ }^{1}$
}

\author{
Physical education academic contents in the students' \\ perspective: a systematic review of productions of area
}

\section{Los contenidos de la enseñanza de la educación física desde la perspectiva de los estudiantes: una revisión sistemática de las producciones del área}

\author{
(iD) Bruna Almeida Ribeiro \\ Universidade Federal do Espírito Santo (UFES) - Vitória/ES - Brasil \\ e-mail:123.bruna@gmail.com \\ iD 9 Rodrigo Lema Del Rio Martins \\ Universidade Federal Rural do Rio de Janeiro (UFRRJ) - Seropédica/RJ - Brasil \\ e-mail: rodrigodrmartins@ufrrj.br \\ iD André da Silva Mello \\ Universidade Federal do Espírito Santo (UFES) - Vitória/ES - Brasil \\ e-mail: andremellovix@gmail.com
}

\begin{abstract}
Resumo: Este estudo analisa, por meio de uma Revisão Sistemática, como a produção acadêmico-científico da Educação Física tem dialogado com os estudantes sobre os conteúdos de ensino mobilizados no Ensino Fundamental. Utiliza como fontes as seguintes bases de dados: LILACS; SciELO; SCOPUS; e Portal de Periódicos da Capes. Os 46 artigos encontrados foram agrupados em três categorias de análise: representações discentes, gênero e conteúdos específicos. Apesar de auscultarem os estudantes, poucas pesquisas buscaram compreender os sentidos e as expectativas desses sujeitos. A maioria dos textos focalizou a opinião dos estudantes sobre as estratégias pedagógicas adotadas pelos do-
\end{abstract}

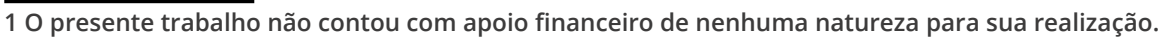


centes, explicitando, dessa forma, o lugar periférico que ocupam nessas pesquisas.

Palavras-Chave: Educação Física. Ensino Fundamental. Conteúdos de ensino. Estudantes.

Abstract: The work analyzes, through a Systematic Review, the way the Physical Education academic-scientific production has discussed with the students regarding the teaching contents mobilized in Elementary School. It uses as sources the following database: LILACS; SciELO; SCOPUS; and Capes Periodical Portal. The 46 papers found were gathered into three analysis categories: learners representations, gender and specific contents. Despite auscultating the students, only a few researchers aimed at understanding their senses and their expectations. Most of the texts focused on the students' opinion on the pedagogical strategies used by the Teachers, making explicit, thus, the periferic place they occupy in these researches.

Keywords: Physical Education. Elementary Education. Academic contents. Students.

Resumen: Analiza, a través de una Revisión Sistemática, cómo la producción académico-científica de la Educación Física ha dialogado con los estudiantes sobre los contenidos didácticos movilizados en Educación Primaria. Utiliza como fuentes las siguientes bases de datos: LILACS; SciELO; SCOPUS; e y Portal de Revistas de Capes. Los 46 artículos encontrados se agruparon en tres categorías de análisis: representaciones de estudiantes, género y contenido específico. A pesar de escuchar a los estudiantes, pocos estudios han buscado comprender los significados y expectativas de estos temas. La mayoría de los textos se centraron en la opinión de los estudiantes sobre las estrategias pedagógicas adoptadas por los docentes, explicando así el lugar periférico que ocupan en estas investigaciones.

Palabras clave: Educación Física. Enseñanza fundamental. Contenidos didácticos. Estudiantes.

Submetido em: 15-02-2021

Aceito em: 07-07-2021 
Os conteúdos de ensino da educação física na perspectiva dos estudantes: uma revisão... Bruna Almeida Ribeiro • Rodrigo Lema Del Rio Martins • André da Silva Mello

\section{Introdução}

A educação, de maneira geral, e a Educação Física (EF), em particular, historicamente vêm desenvolvendo as suas práticas por meio de modelos pedagógicos externamente orientados, centrados, sobretudo, nos professores, que colocam em segundo plano ou ignoram a participação dos estudantes em seus processos de ensino-aprendizagem, desconsiderando a capacidade desses sujeitos de pensar e agir sobre si. Esses modelos mecânicos de educação, em que os estudantes são considerados como receptáculos vazios, que recebem passivamente os conteúdos escolares "depositados" pelos professores, foi denominado por Freire (1996) de "Educação Bancária".

No caso específico da EF, é cada vez mais nítida a evasão dos estudantes das aulas dessa disciplina, principalmente nas séries finais do Ensino Fundamental e no Ensino Médio, caracterizando o processo de "desescolarização da Educação Física", movimento identificado no início do século XXI (MARTINS; PIMENTEL; MELLO, 2020). Paradoxalmente a isso, percebe-se, com frequência, a participação de adolescentes e jovens em atividades físicas e esportivas em períodos extraescolares, ou seja, esses sujeitos se negam a participar das aulas de EF, mas praticam essas atividades fora da escola.

Uma das razões para que isso ocorra, é a falta de diálogo dos professores com os sujeitos da aprendizagem. Ao trabalhar os conteúdos de forma verticalizada, de cima para baixo, as subjetividades, os interesses e as necessidades dos estudantes não são consideradas.

Certeau (2014) afirma que os praticantes, no cotidiano, não absorvem passivamente os bens culturais que lhes são ofertados. Para o autor, a cultura só faz sentido em seu uso, portanto, compreender e valorizar o consumo produtivo que os sujeitos imprimem aos artefatos culturais é uma maneira de considerar o seu protagonismo nos processos educativos desencadeados 
Os conteúdos de ensino da educação física na perspectiva dos estudantes: uma revisão... Bruna Almeida Ribeiro • Rodrigo Lema Del Rio Martins • André da Silva Mello

pela escola. A valorização das agências dos estudantes, o reconhecimento de suas autorias e de suas produções culturais são pressupostos pedagógicos que estão presentes nos documentos que orientam a Educação Básica no país (BRASIL, 2013; 2017).

Se, por um lado, é possível verificar a centralidade dos estudantes nos referidos documentos, por outro, percebe-se que essa perspectiva ainda está distante de se materializar nos cotidianos escolares. Para compreender como essa temática tem sido discutida no campo da EF, indagamos: De que forma as falas dos estudantes têm sido consideradas nas pesquisas desenvolvidas pelo campo, em especial, àquelas destinadas a discutir os conteúdos de ensino no Ensino Fundamental?

Busca-se, por meio dessa indagação, superar perspectivas de investigação sobre os estudantes por pesquisas com eles desenvolvidas. Nesse sentido, este artigo tem como objetivo analisar, por meio de uma Revisão Sistemática, como a produção acadêmico-científica da EF tem dialogado com os estudantes sobre os conteúdos de ensino mobilizados por essa disciplina no Ensino Fundamental.

\section{Percurso metodológico}

Adotamos a Revisão Sistemática para compreender como o campo acadêmico discute os conteúdos da EF no Ensino Fundamental. A Revisão Sistemática reúne pesquisas sobre determinado objeto, a fim de desenvolver discussões e preencher lacunas presentes no campo científico, colaborando para gerar novos estudos (GOMES; CAMINHA, 2014). Neste artigo, utilizamos como fontes quatro bases de dados eletrônicas: LILACS, SciELO, SCOPUS e Portal de Periódicos da Capes. Essas bases são meios de circulação de importantes periódicos da EF e dispõem de credibilidade da comunidade acadêmico-científica.

Os descritores para a busca dos artigos foram: conteúdos de ensino; seleção de conteúdos e EF escolar. Utilizamos os seguin- 
Os conteúdos de ensino da educação física na perspectiva dos estudantes: uma revisão... Bruna Almeida Ribeiro • Rodrigo Lema Del Rio Martins • André da Silva Mello

tes critérios de inclusão: publicações de 2009 a 2019, para mapear o que está sendo discutido de mais atual pelo campo da EF. Empregamos a periodicidade de 11 anos, pois a "vida média" da literatura nas subáreas Sociocultural e Pedagógica da EF é de, aproximadamente, 11,1 anos (CARNEIRO; FERREIRA NETO; SANTOS, 2020).

Focalizamos os artigos que discutem os conteúdos de ensino da EF no Ensino Fundamental2 escritos em língua portuguesa, revisados por pares. Foram excluídas produções acadêmicas anteriores a 2009, artigos que discutem conteúdos exclusivamente ${ }^{3}$ no Ensino Médio e na Educação Infantil; e artigos de autores estrangeiros.

Para a seleção dos artigos, realizamos a leitura dos títulos, dos resumos e das palavras-chave, considerando os critérios de inclusão/exclusão estabelecidos. Quando os títulos e os resumos não eram esclarecedores, efetuamos a leitura dos textos na íntegra. Na primeira etapa do levantamento bibliográfico mapeamos 165 artigos. Após a leitura flutuante (BARDIN, 2011), em que estabelecemos um contato mais próximo com o material, selecionamos 142 artigos para análise. Ao refinarmos a nossa busca, com foco nas investigações que tinham os estudantes como sujeitos da pesquisa, chegamos a um número final de 46 produções.

\section{Apresentação e análise dos dados}

As metodologias empregadas nos 46 textos, que assumem como sujeitos da pesquisa os estudantes, revelam uma forte presença da pesquisa de campo, materializada por meio da etnografia, da pesquisa-ação, da pesquisa descritiva e dos relatos de experiência. ${ }^{4}$ Os pesquisadores procuraram compreender as

\footnotetext{
2 Escolhemos o Ensino Fundamental por ser a etapa mais longa da escolarização e pela EF estar mais consolidada nela (MARTINS; PIMENTEL; MELLO, 2020).

3 Não excluímos artigos que contemplam o Ensino Fundamental juntamente a outra etapa da Educação Básica, por acreditamos que possuem dados relevantes para a pesquisa.

4 Embora seja questionável classificar o relato de experiência como um método de pesquisa, neste artigo, será considerado pelas características de imersão no cotidiano escolar, fato que permite evidenciar valiosas vivências que podem inspirar novas práticas pedagógicas.
} 
Os conteúdos de ensino da educação física na perspectiva dos estudantes: uma revisão... Bruna Almeida Ribeiro • Rodrigo Lema Del Rio Martins • André da Silva Mello

práticas sociais e/ou opiniões dos atores do cotidiano escolar, privilegiando a adoção de narrativas, entrevistas ou questionários, aplicados, majoritariamente, aos discentes. Em alguns casos, esses instrumentos também serviram para dialogar com docentes, funcionários e familiares.

O questionário e a entrevista, respectivamente, foram os instrumentos mais utilizados na produção de dados. O questionário, por não exigir a presença física do pesquisador no campo, nem sempre confere protagonismo aos sujeitos envolvidos. Eles podem ser adotados dissociados da observação do cotidiano escolar, aferindo apenas a opinião dos educandos a respeito dos conteúdos de ensino. Outra limitação consiste na imutabilidade das questões, que pode gerar resultados aquém do potencial de interlocução com os participantes.

A entrevista, quando adequadamente empregada, pode potencializar a produção de dados, dando voz aos sujeitos, a fim de compreender as suas representações, sentidos e significados a respeito de determinado tema. Outra vantagem da entrevista é o fato de ser passível de reformulação e de acréscimos de perguntas para esclarecer as respostas e garantir resultados mais amplos.

Os 46 artigos, que abordam os conteúdos de ensino na perspectiva dos estudantes, foram classificados em três categorias temáticas: representações discentes, gênero e conteúdos específicos. O Gráfico 1 indica o percentual de artigos relacionado a cada categoria: 
Os conteúdos de ensino da educação física na perspectiva dos estudantes: uma revisão... Bruna Almeida Ribeiro • Rodrigo Lema Del Rio Martins • André da Silva Mello

\section{Gráfico 1 - Distribuição percentual das categorias temáticas}

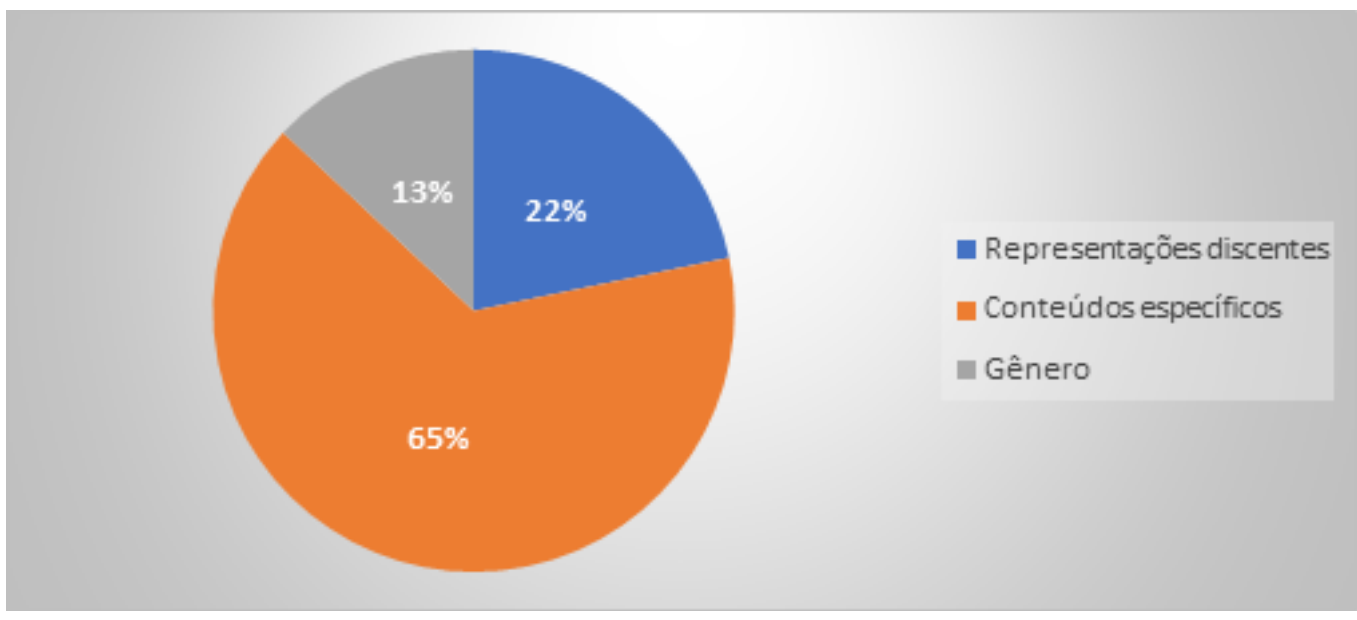

Fonte: Os autores.

\section{Gênero}

As questões de gênero atravessam a nossa sociedade, exigindo reflexões e ações que caminhem no sentido da superação das desigualdades entre homens e mulheres. $\mathrm{Na} E F$, questões como a separação das aulas por gênero, diferentes práticas corporais destinadas para os homens e para as mulheres, diferenças de habilidades e capacidades explicadas pelo sexo, são desafios históricos que precisam ser superados.

Nesta categoria estão reunidos os artigos que focalizaram a participação feminina e masculina nas aulas de EF, o papel do professor diante das relações assimétricas de poder entre meninos e meninas, bem como as questões relacionadas a determinados conteúdos esportivos destinados aos homens ou às mulheres (KERNE, 2014; UCHOGA; ALTMANN, 2015; JACÓ; ALTMANN, 2016; SO; MARTINS; BETTI, 2018; ALTAMANN et al. 2018; GARCIA; BRITO, 2018).

Uchoga e Altmann (2015) destacam que fatores como a confiança nas próprias habilidades e arriscar-se em novos aprendizados interferem na participação de meninos e meninas nas au- 
Os conteúdos de ensino da educação física na perspectiva dos estudantes: uma revisão... Bruna Almeida Ribeiro • Rodrigo Lema Del Rio Martins • André da Silva Mello

las de $E F$, ocasionando um maior envolvimento masculino nessa disciplina. Em sentido complementar, So, Martins e Betti (2018) identificaram a vergonha de se expor como fator limitador para a participação efetiva das meninas nas aulas de EF.

Todos os artigos que versam sobre a relação de gênero com os conteúdos de ensino, a partir da interlocução com os discentes, defendem que os professores precisam criar estratégias que promovam aulas inclusivas para meninos e meninas. Combater preconceitos, estigmas e estereótipos relacionados as práticas corporais, dentro e fora da escola, também aparece como uma tarefa inadiável para todos os atores escolares.

Para Louro (2009), a forma como compreendemos as relações de gênero é histórica, cultural e aprendida. Portanto, recaem sobre as instituições educacionais um papel de destaque, não no sentido de normatizá-las, mas para favorecer um processo de formação inclusivo. Em nossa avaliação, para que a escola avance no combate aos estigmas relacionados ao gênero, também é necessário fortalecer a formação docente.

\section{Representações discentes}

Os artigos que focalizaram as percepções dos estudantes em relação ao modo como os conteúdos são tratados no currículo, permitindo inferências a respeito da relação dos sujeitos com os saberes escolares, foram agrupados na categoria representações discentes (FOLLE; TEIXEIRA, 2012; TENÓRIO; SILVA, 2014; OLIVEIRA; DAOLIO, 2014; CARVALHO, 2015; SILVA; SILVA, 2015; FREITAS et al., 2016; SANTOS et al., 2016; COSTA et al., 2017; TOIGO; MEDEIROS; BRAUNER, 2018; GUIMARÃES; FOLLE; VEIGA, 2019). São textos que apontam para o reconhecimento dos estudantes do Ensino Fundamental como sujeitos centrais da aprendizagem, valorizando as suas falas e o seu protagonismo nos processos educativos. Conforme aponta Freitas et al. (2016), o diálogo com os discentes 
Os conteúdos de ensino da educação física na perspectiva dos estudantes: uma revisão... Bruna Almeida Ribeiro • Rodrigo Lema Del Rio Martins • André da Silva Mello

e o respeito às suas demandas e opiniões favorecem uma visão positiva do papel da EF, do professor e dos estudantes.

Os artigos também destacam fatores envolvidos no ensino dos conteúdos da EF, que geram motivação/desmotivação para a participação efetiva dos estudantes. Folle e Teixeira (2012) afirmam que o fato de a EF se caracterizar como uma disciplina que é ministrada, predominantemente fora do ambiente de sala de aula, estimula o engajamento nas atividades propostas pelos professores. Contudo, os conteúdos e a forma como são trabalhados nas aulas são apontados como os principal fator de resistências à participação dos estudantes.

Tenório e Silva (2015) discutem que o formato de aulas tradicionais, em que o ensino ocorre exclusivamente por meio de atividades práticas, com a repetição dos mesmos conteúdos ao longo de todo o ciclo escolarização, é a principal queixa dos estudantes do Ensino Fundamental. Eles não compreendem o sentido da EF no currículo escolar e alegam que os professores não demonstram a sua relevância para a formação humana. Por outro lado, o diálogo com os discentes, revela a valorização da EF como espaço-tempo privilegiado para a constituição de relações interpessoais.

No estudo de Toigo, Medeiros e Brauner (2018), as percepções discentes sobre as aulas de EF foram analisadas a partir do modo como é desenvolvido o conteúdo nas aulas, a expectativa de aprendizado dos alunos e a visão deles sobre o que aprenderam. Os alunos afirmam desconhecer a importância e a utilidade da disciplina para a sua formação, porém destacam a alegria em participarem das aulas. Na esteira desse debate, Santos et al. (2016, p. 16, grifo dos autores) informam que:

As formas como os discentes significam a EF também demonstram a complexidade do ensinar e, especialmente, do aprender. Elas anunciam o desafio, no campo da pesquisa e da atuação do professor, de compreendermos o que os alunos fazem com a diversidade daquilo que aprendem. Na produção deste trabaIho, percebemos que eles aprendem os conteúdos específicos 
Os conteúdos de ensino da educação física na perspectiva dos estudantes: uma revisão... Bruna Almeida Ribeiro • Rodrigo Lema Del Rio Martins • André da Silva Mello

da EF, porém é pelas práticas com os outros que aprendem a ser e a como ser.

O desinteresse pelas aulas de EF também é discutido no texto de Oliveira e Daolio (2014). Os autores identificaram um comportamento que denominaram de "periferia da quadra", no qual os estudantes do Ensino Fundamental se sentem pouco atraídos em participar de aulas que enfatizam a técnica e a performance na execução das práticas corporais, ou seja, apenas a dimensão procedimental do conteúdo. Parte dos discentes prefere agrupar-se nos cantos da quadra, nas arquibancadas e em outros espaços da escola para conversar, brincar, ouvir música ou assistir aos colegas participando da aula. Oliveira e Daolio (2014) defendem que os professores dialoguem e reconheçam os interesses dos alunos, estruturando práticas pedagógicas que contemplem as dimensões conceituais, procedimentais e atitudinais dos conteúdos.

A crítica direcionada ao ensino da EF, com ênfase na dimensão procedimental, é algo recorrente na área (DARIDO; RANGEL, 2017). Esse cenário está ancorado em "[...] códigos e símbolos demarcados por uma tradição, a qual valoriza um tipo de saber em detrimento de outras formas de aprender" (SANTOS et al., 2016, p. 16). Articular as dimensões conceituais, procedimentais e atitudinais é condição fundamental para que a EF alcance o seu reconhecimento, por parte dos estudantes, no currículo escolar. Concordamos com Darido (2012, p. 55), quando afirma que

[...] os conteúdos são os meios pelos quais o aluno deve analisar e abordar a realidade de forma que, com isso, possa ser construída uma rede de significados em torno do que se aprende na escola e do que se vive.

Guimarães, Folle e Veiga (2019) argumentam que os processos didáticos na EF devem reunir essas três dimensões do conhecimento de forma indissociável, desde a definição dos objetivos das aulas, até os processos avaliativos empregados nessa disciplina. 
Os conteúdos de ensino da educação física na perspectiva dos estudantes: uma revisão... Bruna Almeida Ribeiro • Rodrigo Lema Del Rio Martins • André da Silva Mello

A partir de um relato de experiência com turmas dos anos finais do Ensino Fundamental, indicamos possibilidades de efetivar uma proposta pedagógica dessa natureza, contemplando uma diversidade de conteúdos, bem como dinamizando a avaliação da aprendizagem e a autonomia discente.

A compreensão, por parte dos discentes, sobre o papel da EF no currículo escolar é relevante. Concordamos que os conhecimentos tratados no contexto escolar se materializam por meio das relações com os saberes, que são apropriados de forma particulares pelos sujeitos das aprendizagens, em um processo que conjuga a relação dos indivíduos com o conhecimento, com o mundo, com o outro e consigo mesmo (CHARLOT, 2000). A relação epistêmica com os saberes faz emergir as seguintes figuras do aprender: objetivação-denominação, imbricação do eu e distanciação-regulação. ${ }^{5}$ Santos et al. (2016) sinalizam que a EF precisa avançar no sentido de valorizar todas essas figuras do aprender, qualificando os processos de ensino-aprendizagem. Portanto, ainda que a $E F$, em função das suas especificidades, mantenha interface maior com a imbricação do eu, não pode prescindir das demais figuras do aprender.

Em nossa avaliação, o interesse dos alunos pela EF passa pelos conteúdos de ensino a serem desenvolvidos nas aulas, podendo gerar maior ou menor adesão, mas, também, pelas decisões didáticas do professor. Essas dimensões impactam diretamente nas representações discentes acerca da EF como componente curricular. Com base nos textos analisados, compreendemos que as práticas pedagógicas da EF precisam estar assentadas em processos de ensino-aprendizagem que considerem as percepções e os sentidos atribuídos pelos estudantes, contemplando as dimensões conceituais, procedimentais e atitudinais dos conteúdos e as diferentes figuras do aprender.

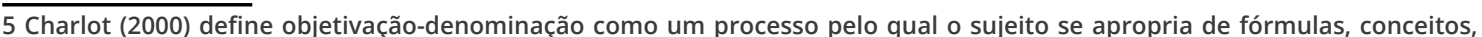
teorias etc., que se caracterizam como um capital simbólico; a imbricação do eu refere-se ao domínio das atividades que ainda não foram plenamente adquiridas pelos sujeitos. Esse domínio está intimamente ligado ao corpo, pois é nele que esse tipo de saber se inscreve; a distanciação-regulação, por sua vez, é um processo relacional com o mundo no qual o indivíduo está inserido, com os demais sujeitos que interage e consigo mesmo.
} 
Os conteúdos de ensino da educação física na perspectiva dos estudantes: uma revisão... Bruna Almeida Ribeiro • Rodrigo Lema Del Rio Martins • André da Silva Mello

\section{Conteúdos específicos da EF}

Na categoria conteúdos específicos, foram reunidos os artigos que versam sobre propostas de ensino de um objeto de conhecimento particular. Tratam-se de discussões realizadas em sala de aula sobre o assunto, das vivências corporais nas quadras e demais espaços da escola, mediada pelo objeto de ensino em questão. Identificamos 30 publicações com essas características. Metade enfatiza os esportes, seja de forma geral ou com foco em uma determinada modalidade. A outra metade aponta para uma variedade significativa de práticas corporais, possíveis de serem exploradas nas aulas de EF, tais como: práticas de aventura, atividades circenses, danças, ginástica, lutas/capoeira, jogos/brincadeiras e saúde e habilidades motoras. O Gráfico 2 retrata essa distribuição numérica:

\section{Gráfico 2 - Conteúdos específicos}

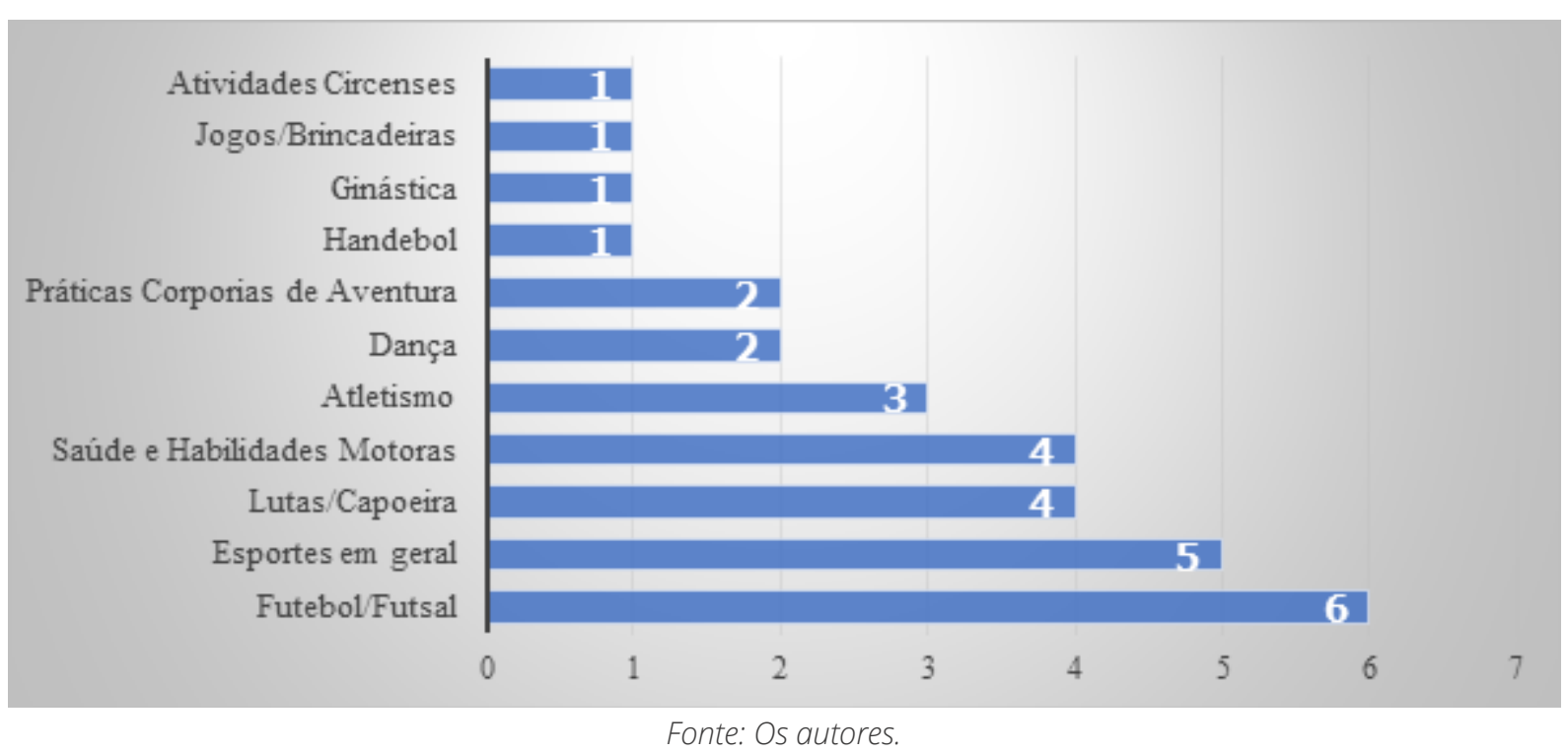

Fonte: Os autores.

Essa variedade de conteúdos sinaliza para uma importante ampliação do rol de manifestações da cultura de movimento que vem sendo trabalhadas na EF escolar. Diversificar os conteúdos, associado a um planejamento que seja fruto do diálogo constante 
Os conteúdos de ensino da educação física na perspectiva dos estudantes: uma revisão... Bruna Almeida Ribeiro • Rodrigo Lema Del Rio Martins • André da Silva Mello

com os discentes, pode reforçar a importância da EF e justificar a sua presença na escola (KAWASHIMA; SOUZA; FERREIRA, 2009).

As publicações inseridas na categoria conteúdos específicos defendem, política e pedagogicamente, a necessidade de superar uma visão histórica de EF escolar como sinônimo de esportes (ARAÚJO; ROCHA; BOSSLE, 2018). A predominância esportiva ainda é latente, mas já não é possível afirmar haver uma hegemonia indiscutível ou uma "monocultura esportiva", como afirma Bracht (2006).

Dos 15 artigos que tratam do esporte como conteúdo específico nas aulas de EF, observamos que o futebol/futsal (BASTOS; NAVARRO, 2009; BUSSO; DAOLIO, 2011; MACAGNAN; BETTI, 2014; FARIA, 2014; ZAREMBA; NAVARRO, 2016; SILVA; RICHTER; PINTO, 2017), embora em maior número, dividem espaço com outras modalidades esportivas Além dessas modalidades, há um conjunto de artigos (PIMENTA; HONORATO, 2010; FRIZZO, 2013; COLEDAM et al., 2014; SEDORKO; FINCK, 2016; COSTA et al., 2018) que optou por analisar os conteúdos de ensino pela ótica dos esportes em geral, enfatizando a diversificação de modalidades que se fazem presentes no currículo de Ensino Fundamental. Portanto, não há uma predominância explícita de uma modalidade, tampouco as produções se concentram no tradicional "quarteto fantástico" (futebol, handebol, basquete e voleibol).

A crítica a uma EF esportivizante é uma importante contribuição de pesquisadores à EF brasileira. Contudo, essa crítica precisa ser revisada à luz de novas produções. Em termos documentais, os PCNs, as DCNs e a BNCC defendem uma EF capaz de promover experiências corporais diversificadas, em diálogo com os condicionantes socioculturais que incidem sobre elas. Os dados produzidos nesta revisão indicam que essa perspectiva está em curso. Portanto, não podemos examinar a presença dos esportes nas aulas de EF pela ótica do que ele foi ou do que deveria ser, mas sim, de como vem sendo, ou seja, como vem se constituindo nos relatos de experiências e nas pesquisas de campo que assumem 
Os conteúdos de ensino da educação física na perspectiva dos estudantes: uma revisão... Bruna Almeida Ribeiro • Rodrigo Lema Del Rio Martins • André da Silva Mello

os estudantes (sujeitos da aprendizagem) como interlocutores privilegiados.

A presença contundente dos esportes nas aulas de EF é compreensível, pois trata-se de uma manifestação da cultura corporal que congrega um conjunto amplo de modalidades. Por essa razão, o esporte permite que os professores tenham uma gama considerável de práticas corporais a serem desenvolvidas em suas aulas, ainda que pese a influência das modalidades consagradas.

O esporte é uma manifestação cultural presente na vida das pessoas, que, em certa medida, explica a sua predileção por parte dos estudantes. Portanto, não se trata de algo negativo em si, que deve ser substituído nas aulas de EF. Pelo contrário, como manifestação social, de abrangência mundial, é um conteúdo programático a ser abordado desde as séries iniciais, porém, precisa ser ensinado e problematizado em diferentes dimensões e não apenas praticado irrefletidamente.

Os artigos analisados apontam o caráter polissêmico do esporte, que culmina com uma variedade de perspectivas pedagógicas pelas quais estão sendo trabalhados com os estudantes do Ensino Fundamental. Em diversos textos, percebemos propostas ancoradas em abordagens críticas acerca dos esportes, que contribuem para superar uma visão tecnicista de ensino, ainda tão propalada na área da EF.

Parte dos textos analisados defendem que, ao invés de questionar a presença do esporte na escola, deve-se problematizar a maneira como ele vem se desenvolvendo nesse contexto. Esses artigos reforçam a necessidade de transpor didaticamente o esporte de alto rendimento para um esporte adequado as demandas formativas das escolas. Para os autores, as escolas não devem reproduzir o modelo performático, com ênfase na competição, mas trabalhar o esporte da escola (CAPARRÓZ, 2007), dialogando com temáticas recorrentes na sociedade que envolvam a sua prática, como a mídia, a política, os interesses econômicos e, até mesmo, o esporte de alto rendimento. 
Os conteúdos de ensino da educação física na perspectiva dos estudantes: uma revisão... Bruna Almeida Ribeiro • Rodrigo Lema Del Rio Martins • André da Silva Mello

Os artigos que abordam as lutas (ALENCAR et al., 2015; LOPES; KERR, 2015; CRUZ et al., 2018; SILVA et al., 2018) apontam caminhos para o ensino desse conteúdo nas aulas de EF, por meio de propostas de práticas pedagógicas e relatos de experiências para auxiliar professores na abordagem do tema. Os textos questionam a pouca adesão das lutas como conteúdo pelos professores de $E F$, apesar de os documentos norteadores ${ }^{6}$ recomendarem o seu uso.

A falta de domínio do conteúdo por parte dos docentes é apontada como fator limitante para o ensino das lutas na escola. Outros fatores restritivos são o receio com a integridade física dos alunos, desse conteúdo se tornar um catalisador da violência e a formação inicial em EF, que pouco trabalha com essa manifestação da cultura corporal.

O trabalho pedagógico com as habilidades motoras e com temas relativos à saúde se materializam em forma de conteúdos de ensino, com destaque para a abordagem da atividade física na prevenção de doenças e na utilização de circuitos motores para desenvolver as habilidades locomotoras, manipulativas e estabilizadores dos discentes. Os artigos (SILVEIRA et al., 2013; SILVA; BAPTISTA, 2014; JESUS; VIEIRA; COPETTI, 2014; CREMONESI; BANKOFF; ZAMAI, 2014) reconhecem que apenas transmitir informações a respeito do corpo, doenças e hábitos de higiene é insuficiente para desenvolver atitudes consideradas saudáveis para o indivíduo. Em propostas de ensino sobre o tema, os autores constataram, sem desconsiderar a importância de abordagens teóricas a respeito da saúde, que as intervenções pedagógicas de caráter prático, com foco nas vivências corporais, proporcionaram a apropriação mais eficiente sobre o tema, favorecendo que os estudantes construam hábitos saudáveis em seus cotidianos, de acordo com os seus relatos.

As danças aparecem nos textos analisados (SHIBUKAWA et al., 2011; VIEIRA; FREIRE; RODRIGUES, 2018), indicando que elas costumam ser trabalhadas na escola, majoritariamente, em datas

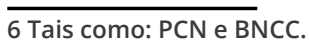


Os conteúdos de ensino da educação física na perspectiva dos estudantes: uma revisão... Bruna Almeida Ribeiro • Rodrigo Lema Del Rio Martins • André da Silva Mello

comemorativas, como a festa junina, e em eventos extraclasse. Os alunos relataram a predominância de abordagens coreografadas, que priorizam a execução de movimentos estereotipados e sincronizados, dentro de padrões pré-determinados. Em sentido oposto, os autores enfatizam que as danças na escola são formas de expressão corporal, que devem contribuir para formação de cidadãos críticos, desenvolvendo a autoexpressão e estimulando a participação dos alunos.

O trabalho de Maldonado e Bocchini (2015) apontou a necessidade de oferecer um olhar pedagógico para a ginástica que é ensinada na escola, pois os alunos sinalizam que o contato que têm com essa modalidade é muito limitado e que não contempla as suas diferentes perspectivas. Já as práticas corporais de aventura são conteúdos que favorecem uma docência integrativa, com alto potencial para estabelecer a interdisciplinaridade da EF com outros componentes curriculares, a partir das discussões sobre a educação ambiental (ARAÚjO et al., 2012; ZAGARE, 2015). Contudo, na relação com os alunos, os autores buscaram experimentar propostas de práticas corporais que não se restringiram à aprendizagem de questões ecológicas e ambientais, mas também como uma manifestação da cultura de movimento que precisa ser socializada pela EF.

O atletismo é focalizado em três manuscritos (LECOT; SILVEIRA, 2014; GINCIENE; MATTHIESEN, 2017; ROSA et al., 2017). O ponto em comum entre eles é a defesa de que o atletismo, para ser mais difundido no Ensino Fundamental, precisa superar a tradicional alegação dos professores de que as escolas não são adequadamente equipadas para essa modalidade. Os autores argumentam que existem possibilidades de trabalhar pedagogicamente o atletismo por meio de materiais não estruturados e adaptações espaciais, envolvendo os discentes nessa construção, de modo que os estudantes não sejam alijados desse conhecimento.

Acerca do jogo como conteúdo específico do Ensino Fundamental (MALDONADO; SILVA, 2016), os autores recomendam contemplá-lo por meio das dimensões conceituais, procedi- 
Os conteúdos de ensino da educação física na perspectiva dos estudantes: uma revisão... Bruna Almeida Ribeiro • Rodrigo Lema Del Rio Martins • André da Silva Mello

mentais e atitudinais. O estudo afirma que é possível estimular o pensamento crítico dos estudantes sobre essa manifestação da cultura corporal de movimento e que os diferentes formatos de jogos se constituem como um importante meio para o desenvolvimento das múltiplas inteligências. A partir dos relatos dos estudantes, os autores sinalizam que é viável estabelecer um processo de ensino-aprendizagem lastreado pelo repertório cultural desses sujeitos sobre os jogos.

Dentre as produções analisadas, naquelas classificadas nas categorias gênero e representações discentes (16), verificamos que os estudantes constituíram-se como informantes privilegiados sobre suas representações, expectativas e compreensões do papel da EF no currículo escolar, Entretanto, os textos que abordam os conteúdos específicos (30), em especial, os estudos sobre os esportes, sinalizam para uma participação mais consultiva dos alunos, no sentido de verificar a sua aceitação em relação a determinados conteúdos ou a metodologias de ensino empregadas pelos professores/pesquisadores.

Assim como compreendemos que a predominância dos esportes nas aulas de EF não é um problema em si, por considerarmos que o modo como eles são trabalhados pedagogicamente é o mais relevante. Também defendemos um modelo pedagógico que potencializa a interlocução com os discentes, capaz de conferir o protagonismo juvenil, em que suas demandas e interesses sejam levados em consideração nos processos de ensino-aprendizagem com eles desenvolvidos.

\section{Considerações finais}

A participação dos discentes nos processos de escolha e de abordagem dos conteúdos de ensino não exime os professores de suas responsabilidades didático-pedagógicas, pelo contrário, torna esse processo muito mais complexo e desafiador para o docente, diante da imprevisibilidade e da diversidade de caminhos 
Os conteúdos de ensino da educação física na perspectiva dos estudantes: uma revisão... Bruna Almeida Ribeiro • Rodrigo Lema Del Rio Martins • André da Silva Mello

que as aulas podem tomar. Kohan (2020), ao discutir o processo de ensino-aprendizagem centrado nos estudantes, utiliza a metáfora da viagem. Para ele, mais importante do que conhecer o destino final da viagem, é construir os diferentes percursos que serão trilhados para alcançá-lo. Os diferentes percursos são estabelecidos a partir das subjetividades, dos interesses, das agências e das produções culturais dos alunos, tornando as aprendizagens significativas para eles.

Dos 142 artigos que abordam os conteúdos de ensino na EF no Ensino Fundamental, 46 dão voz e visibilidade aos estudantes, ou seja, um pouco menos de 1/3 do material analisado recorre à opinião dos alunos sobre a temática em questão. Ao considerarmos a trajetória dessa disciplina na escola, esse número é bastante expressivo, pois rompe com uma lógica de ensino centrada no desenvolvimento das técnicas esportivas, cujo principal agente é o professor, cabendo aos discentes apenas repetir gestos mecânicos e estereotipados.

Contudo, com exceção dos artigos relacionados às categorias representações discentes e gênero, a maior parte dos textos analisados (30 de 46) e que estão associados à categoria conteúdos específicos, recorrem a opinião dos alunos apenas para validar os processos pedagógicos ou as perspectivas de ensino que os autores difundiram em suas pesquisas e relatos. Nesse sentido, a fala desses sujeitos é utilizada apenas para legitimar os procedimentos pedagógicos adotados, reduzindo o seu alcance e limitando a participação dos estudantes a aspectos pontuais em relação aos conteúdos de ensino.

Retirar os estudantes da condição de subalternidade em relação aos docentes, considerá-los como sujeitos sociais ativos em seus processos de aprendizagem e desenvolvimento, por meio do reconhecimento e valorização de suas agências, é uma necessidade premente para que a EF ganhe relevância e sentido na escola contemporânea. Para Santos (2020), é preciso que o conhecimento seja produzido com o mundo e não sobre ele. Nesse sentido, os discentes deixam de ser meros informantes, tornando-se copar- 
Os conteúdos de ensino da educação física na perspectiva dos estudantes: uma revisão...

Bruna Almeida Ribeiro • Rodrigo Lema Del Rio Martins • André da Silva Mello

ceiros na construção dos conhecimentos, vozes autorizadas para pensar e falar sobre si.

\section{Referências}

ALENCAR, Yllah Oliveira et al. As lutas no ambiente escolar: uma proposta de prática pedagógica. Revista Brasileira de Ciências e Movimento, Brasília, v. 23, n. 3, p. 53-63, jul./set. 2015.

ALTMANN, Helena et al. Gênero e cultura corporal de movimento: práticas e percepções de meninas e meninos. Revista Estudos Feministas, Florianópolis, v. 26, n. 1, p. 1-16, 2018.

ARAUJO, Mauricio Pires de et al. Contribuição de diferentes conteúdos das aulas de educação física no ensino fundamental para o desenvolvimento das habilidades motoras fundamentais. Revista Brasileira de Medicina do Esporte, São Paulo, v. 18, n. 3, p. 153-157, mai./jun. 2012.

ARAÚJO, Samuel Nascimento de; ROCHA, Leandro Oliveira; BOSSLE, Fabiano. Os conteúdos de ensino da Educação Física escolar: um estudo de revisão nos periódicos nacionais da Área 21. Motrivivência, Florianópolis, v. 29, n. 51, p. 205-221, jul. 2017. BARDIN, Laurence. Análise de conteúdo. Brasil: Edições 70 Brasil, 2011.

BASTOS, Paula Viotti; NAVARRO, Antonio Coppi. Revista

Brasileira de Futsal e Futebol, São Paulo, v. 1, n. 2, p. 144-162, maio./ago. 2009.

BRACHT, Valter. Cultura corporal e esporte escolar: fator de inclusão e desenvolvimento social? In: REZER, Ricardo. (org.). 0 fenômeno esportivo: ensaios crítico-reflexivos. Chapecó/SC: Argos, 2006. p. 123-126.

BRASIL. Base Nacional Comum Curricular. Ministério da Educação. Brasília: MEC, 2017. 
Os conteúdos de ensino da educação física na perspectiva dos estudantes: uma revisão...

Bruna Almeida Ribeiro • Rodrigo Lema Del Rio Martins • André da Silva Mello

BRASIL, Ministério da Educação. Secretaria de Educação

Fundamental. Parâmetros Curriculares Nacionais: $5^{\mathrm{a}}$ a $8^{\mathrm{a}}$ série. Brasília: MEC/SEF, 1998.

BRASIL. Secretaria de Educação Básica. Diretrizes Curriculares

Nacionais Gerais da Educação Básica. Brasília: MEC, SEB, DICEI, 2013.

BUSSO, Gilberto Leandro; DAOLIO, Jocimar. O jogo de futebol no contexto escolar e extraescolar: encontro, confronto e atualização. Revista Brasileira de Ciências do Esporte, Florianópolis, v. 33, n. 1, p. 69-86, jan./mar. 2011.

CAPARROZ, Francisco Eduardo. Entre a educação física na escola e a educação física da escola. Campinas/SP: Autores Associados, 2007.

CARNEIRO, Felipe Ferreira Barros; FERREIRA NETO, Amarílio; SANTOS, Wagner dos. Ciência e Educação Física no Brasil: Análise das Citações Utilizadas nos Artigos das Subáreas Biodinâmica do Movimento e Sociocultural e Pedagógica. Retos, Múrcia-ESP, n. 38, p. 645-653, jul./dez. 2020.

CARVALHO, Leandro Coutinho Vilela de. Fatores para a motivação ou desmotivação à participação nas aulas de educação física.

Revista Brasileira de Futsal e Futebol, São Paulo, v. 7, n. 27, p. 548-553, 2015.

CERTEAU, Michel de. A invenção do cotidiano: artes do fazer. 22. ed. Petrópolis/RJ: Vozes, 2014.

CHARLOT, Bernard. Da relação com o saber: elementos para uma teoria. Porto Alegre: Artmed, 2000.

COLEDAM, Diogo Henrique Constantino et al. Prática esportiva e participação nas aulas de educação física: fatores associados em estudantes de Londrina, Paraná, Brasil. Cadernos de Saúde Pública, Rio de Janeiro, v. 30, n. 3, p. 533-545, mar. 2014.

COSTA, Luciane Cristina Arantes da et al. O esporte na Educação Física Escolar: um conteúdo com potencial emancipador. 
Os conteúdos de ensino da educação física na perspectiva dos estudantes: uma revisão... Bruna Almeida Ribeiro • Rodrigo Lema Del Rio Martins • André da Silva Mello

Movimento, Porto Alegre, v. 24, n. 4, p. 1077-1096, out./dez. 2018.

COSTA, Luciane Cristina Arantes da et al. Educação física e esportes: motivando para a prática cotidiana escolar. Movimento, Porto Alegre, v. 23, n. 3., p. 935-948, jul./set. 2017.

CREMONESI, Lara Novais; BANKOFF, Antonia Dalla Pria; ZAMAI, Carlos Aparecido. Obesidade: uma tentativa de abordagem na Educação Física escolar de $5^{\mathrm{a}}$ à $8^{\mathrm{a}}$ séries. Lúdica Pedagógica, Bogotá-COL, n. 20, p. 119-128, jul./nov. 2014.

CRUZ, Marlon Messias Santana et al. Tematizando as lutas na educação física escolar: relato de uma prática pedagógica no contexto do PIBID. Caderno de Educação Física e Esporte, Marechal Cândido Rondon/PR, v. 16, n. 1, p. 109-115, jan./jun. 2018.

DARIDO, Suraya Cristina; RANGEL, Irene Conceição Andrade. A Educação Física na escola: implicações para a prática pedagógica. 2. ed. Rio de Janeiro: Guanabara Koogan, 2017.

DARIDO, Suraya Cristina. Educação física na escola: conteúdos, suas dimensões e significados. In: UNIVERSIDADE ESTADUAL PAULISTA, Prograd. Caderno de formação: formação de professores didática geral. São Paulo: Cultura Acadêmica, 2012. p. 51-75, v. 16.

FARIA, Eliene Lopes. Quando "rola a bola": reflexões sobre as práticas futebolísticas e a forma escolar nas aulas de Educação Física. Revista Brasileira de Ciências do Esporte, Florianópolis, v. 36, n. 2, p. 501-513, abr./jun. 2014.

FREIRE, Paulo. Pedagogia do Oprimido. São Paulo: Paz e Terra, 1996.

FREITAS, Josiane Filus et al. A identidade da Educação Física escolar sob o olhar dos alunos do $5^{\mathrm{a}}$ ano do Ensino Fundamental I.

Pensar a Prática, Goiânia, v. 19, n. 2, abr./jun. 2016.

FOLLE, Alexandra; TEIXEIRA, Fabiano Augusto. Motivação de escolares das séries finais do Ensino Fundamental nas aulas de 
Os conteúdos de ensino da educação física na perspectiva dos estudantes: uma revisão... Bruna Almeida Ribeiro • Rodrigo Lema Del Rio Martins • André da Silva Mello

Educação Física. Revista de Educação Física/UEM, Maringá/PR, v. 23, n. 1, p. 37-44, 1. trim. 2012.

FRIZZO, Giovanni. Os jogos escolares como mecanismos de manutenção e eliminação: uma crítica à lógica esportiva na escola. Movimento, Porto Alegre, v. 19, n. 04, p. 163-180, out./dez. 2013. GARCIA, Rafael Marques; BRITO, Leandro Teófilo de. Movimento, Porto Alegre, v. 24, n. 4, p. 1321-1334, out./dez. 2018.

GINCIENE, Guy; MATTHIESEN, Sara Quenzer. O modelo do sport education no ensino do atletismo na escola. Movimento, Porto Alegre, v. 23, n. 2, p. 729-742, abr./jun. 2017.

GOMES, Isabelle Sena; CAMINHA, Iraquitan de Oliveira. Guia para estudos de revisão sistemática: uma opção metodológica para as Ciências do Movimento Humano. Movimento, Porto Alegre, v. 20, n. 1, p. 395-411, jan./mar. 2014.

GUIMARÃES, Juliana Regina Silva; FOLLE, Alexandra; VEIGA, Monica Bredun da. Corrida orientada: estratégia para avaliação dos conteúdos da Educação Física escolar. Motrivivência, Florianópolis, v. 31, n. 57, p. 1-16, jan./mar. 2019.

JACÓ, Juliana Fagundes; ALTMANN, Helena. Educação Física Escolar e Gênero: Influências de fora da escola na participação em aulas. Educação, Rio Claro/SP, v. 26, p. 19-35, 2016.

KAWASHIMA, Larissa Beraldo; SOUZA, Laura Beraldo de; FERREIRA, Lílian Aparecida. Sistematização de conteúdos da Educação Física para as séries iniciais. Motriz, Rio Claro/SP, v. 15, n. 2, p. 458-468, abr./jun. 2009.

KERNE, Felipe. Futebol feminino na escola na perspectiva de alunas do ensino fundamental. Revista Brasileira de Futsal e Futebol. São Paulo, v. 6, n. 22, p. 278-285, jan./ dez. 2014.

KOHAN, Walter Omar. Tempos da escola em tempo de pandemia e necropolítica. Práxis Educativa, Ponta Grossa/PR, v. 15, e2016212, 2020.

LECOT, Francisco Matias; SILVEIRA, Rozana Aparecida da. O conhecimento do conteúdo atletismo na educação física escolar. 
Os conteúdos de ensino da educação física na perspectiva dos estudantes: uma revisão... Bruna Almeida Ribeiro • Rodrigo Lema Del Rio Martins • André da Silva Mello

Cinergis, Santa Cruz do Sul/RS, v. 15, n. 3, p. 129-134, jul./set. 2014.

LOPES, Raphael Gregory Bazílio; KERR, Tiemi Okimura. O ensino das lutas na educação física escolar: uma experiência no ensino fundamental. Motrivivência, Florianópolis, v. 27, n. 45, p. 262279, set. 2015.

LOURO, Guacira Lopes. Pensar a sexualidade na contemporaneidade. In: PARANÁ, Secretaria de Estado de Educação (org.). Sexualidade. Curitiba: SEED, 2009. p. 29-35.

MACAGNAN, Leandro Del Giudice; BETTI, Mauro. Futebol: representações e práticas de escolares do ensino fundamental.

Revista Brasileira de Educação Física e Esporte, São Paulo, v. 28, n. 2, p. 315-327, abr./jun. 2014.

MALDONADO, Daniel Teixeira; BOCCHINI, Daniel. Ensino da ginástica na escola pública: as três dimensões do conteúdo e o desenvolvimento do pensamento crítico. Motrivivência, Florianópolis, v. 27, n. 44, p. 164-176, dez./mai. 2015.

MALDONADO, Daniel Teixeira; SILVA, Sheila Aparecida Pereira dos Santos. O jogo como manifestação da cultura corporal de movimento na Educação Física Escolar: as três dimensões do conteúdo e o desenvolvimento do pensamento crítico. Motrivivência, Florianópolis, v. 28, n. 48, p. 386-403, jul./set. 2016.

MARTINS, Rodrigo Lema Del Rio; PIMENTEL, Giuliano Gomes de Assis; MELLO, André da Silva. Editorial do Dossiê: A escolarização da Educação Física no século XXI: desafios contemporâneos.

Revista Humanidades \& Inovação, Palmas, v. 7, n. 10, p. 7-8, abr. 2020.

MATOS, Juliana Cassani et al. A produção acadêmica sobre conteúdos de ensino na educação física escolar. Movimento, Porto Alegre, v. 19, n. 2, p. 123-148, abr./jun. 2013.

OLIVEIRA Rogério Cruz de.; DAOLIO Jocimar. Na "periferia" da quadra: Educação Física, cultura e sociabilidade na escola. ProPosições, Campinas/SP, v. 25, n. 2, p. 237-254, maio/ago. 2014. 
Os conteúdos de ensino da educação física na perspectiva dos estudantes: uma revisão... Bruna Almeida Ribeiro • Rodrigo Lema Del Rio Martins • André da Silva Mello

PIMENTA, Thiago; HONORATO, Tony. Esporte moderno e mediação pedagógica nas aulas de educação física. Revista Brasileira De Educação Física e Esporte, São Paulo, v. 24, n. 4, p. 493-505, out./dez. 2010.

ROSA, Rodolfo Silva da et al. O atletismo como conteúdo vai à escola: olhares discentes sobre a experiência de ensino. Pensar a Prática, Goiânia, v. 20, n. 1, p. 15-25, jan./mar. 2017.

SANTOS, Boaventura Silva. A cruel pedagogia do vírus. Coimbra: Almedina, 2020.

SANTOS, Wagner dos et al. A relação dos alunos com os saberes nas aulas de Educação Física. Journal of Physical Education, Maringá/PR, v. 27, e2737, 2016.

SEDORKO, Clóvis Marcelo; FINCK, Silvia Christina Madrid. Sentidos e significados do esporte no contexto da educação física escolar. Journal Physical Education, Maringá/PR, v. 27, e2745, 2016.

SHIBUKAWA, Rodrigo Massami et al. Revista Brasileira de Educação Física e Esporte, São Paulo, v. 25, n. 1, p. 19-26, jan./ mar. 2011.

SILVA, Junior Vagner Pereira da; SILVA, Luiza Lana Gonçalves. Educação Física nos anos finais do Ensino Fundamental em Campo Grande/MS. Revista Brasileira de Ciência e Movimento, Brasília, v. 23, n. 2, p. 22-31, jun./abr. 2015.

SILVA, Juliana Kanareck da; RICHTER, Ana Cristina; PINTO, Fabio Machado. O sentido do futebol nas aulas de educação física. Movimento, Porto Alegre, v. 23, n. 4, p. 1395-1406, out./dez. 2017.

SILVA, Leandro Ribeiro da et al. O conteúdo de lutas no combate à violência da discriminação e do preconceito na escola mediado por histórias em quadrinhos. Revista EDaPECI, São Cristóvão/SE, v. 18, n. 3, p. 80-92, set./dez. 2018.

SILVA, Matheus Castro da; BAPTISTA, Guilherme Gonçalves. O corpo na/da escola: as possibilidades da Educação Física escolar na (des)construção das representações corporais. Revista 
Os conteúdos de ensino da educação física na perspectiva dos estudantes: uma revisão... Bruna Almeida Ribeiro • Rodrigo Lema Del Rio Martins • André da Silva Mello

Contemporânea de Educação, Rio de Janeiro, v. 9, n. 18, jul./dez. 2014.

SILVEIRA, Sérgio Roberto. Aquisição da habilidade motora rebater na Educação Física escolar: um estudo das dicas de aprendizagem como conteúdo de ensino. Revista Brasileira de Educação Física e Esporte, São Paulo, v. 27, n. 1, p. 149-157, jan/mar. 2013. SO, Roberto; MARTINS, Mariana Zuaneti; BETTI, Mauro. As relações das meninas com os saberes das lutas nas aulas de Educação Física. Motrivivência, Florianópolis, v. 30, n. 56., p. 2948, dez. 2018.

TENÓRIO, Jederson Garbin; SILVA, Cinthia Lopes da. O desinteresse dos estudantes pelas aulas de educação física em uma escola de ensino público do estado de Mato Grosso. Salusvita, Bauru/ SP, v. 34, n. 1, p. 27-44, abr./out. 2015.

TOIGO, Adriana Marques; MEDEIROS, Thaina de Avila; BRAUNER, Luciana Martins. Educação física no ensino fundamental: observação e relato de crianças e professores sobre a aprendizagem dos conteúdos em uma escola pública do município de Esteio, RS. Pensar a Prática, Goiânia, v. 21, n. 2, p. 328-337, abr./jun. 2018. UCHOGA, Liane Aparecida Roveran; ALTMANN, Helena. Educação física escolar e relações de gênero: diferentes modos de participar e arriscar-se nos conteúdos de aula. Revista Brasileira de Ciências do Esporte, v. 38, n. 2, p. 163-170, abr./jun. 2015. VIEIRA, Márcio José Ibarra; JESUS, Rhenan Ferraz de; COPETTI, Jaqueline. Atividade física, diabetes e obesidade nas aulas de educação física: percepções de escolares do $7^{\circ}$ ano. Caderno de Educação Física e Esporte, Marechal Cândido Rondon/PR, v. 12, n. 1, p. 85-93, jan./jun. 2014.

VIEIRA, Pollyane Barros Albuquerque; FREIRE, Elisabete dos Santos; RODRIGUES, Graciele Massoli. Folguedos juninos: o ensino da dança sob a perspectiva das dimensões dos conteúdos. Motrivivência, Florianópolis/SC, v. 30, n. 55, p. 248-257, set. 2018. 
Os conteúdos de ensino da educação física na perspectiva dos estudantes: uma revisão... Bruna Almeida Ribeiro • Rodrigo Lema Del Rio Martins • André da Silva Mello

ZAGARE, Thiago. Aula adaptada de stand up paddle com garrafas pet nas aulas de educação física. Regae: Revista de Gestão e Avaliação Educacional, Santa Maria/RS, v. 4, n. 8, p. 79-95, jul./dez. 2015.

ZAREMBA, Fagner; NAVARRO, Antonio Coppi. O futebol e seus similares no currículo escolar do $9^{\circ}$ ano do ensino fundamental na disciplina de educação física: a aprendizagem por meio da relação teoria e prática. Revista Brasileira de Futsal e Futebol, São Paulo, v. 8, n. 31, p. 348-356, jan./dez. 2016.

\section{Publisher}

Universidade Federal de Goiás. Faculdade de Educação Física e Dança. Publicação no Portal de Periódicos UFG. As ideias expressadas neste artigo são de responsabilidade de seus autores, não representando, necessariamente, a opinião dos editores ou da universidade. 